\title{
Innovation Efficiency Research of Shandong Province under Innovation-driven Strategy
}

\author{
Lei Wang \\ Shandong Transport Vocational College, Weifang, Shandong, 261000, China \\ Email:4977618@qq.com
}

Keywords: Innovation-driven Strategy, Innovation Efficiency

\begin{abstract}
Innovation is the source of a nation's power, and the proposition of innovation strategy has guided the direction for national economic development. As to Shandong Province, how to enhance the provincial comprehensive strength and improve innovation efficiency is a problem worth discussion. Analyzing innovation input and output of Shandong Province during last five years, there is still redundancy and relaxation existed. This analysis fully reflects the execution and popularity of innovation strategy in Shandong, but there are still spaces for improvement of innovation efficiency.

There has been a long-standing phenomenon of unbalance of economic developments in various regions within Shandong Province, but the fundamental cause is that the innovation ability and efficiency varies from one region to another. Therefore, innovation ability is the most competitive inner power of a city or a region.
\end{abstract}

It is clearly proposed at the 18th Party Congress that "to implement an innovation-driven development strategy and to place innovation at the core of the country's overall development". Since the year 2013, Shandong Province has been initiatively transforming economic development mode, which has achieved certain accomplishments, and the comprehensive innovation ability has been ranked to top six in China, at the same time there have been gradual improvements at various aspects with the innovation-driven strategy of transformation reform. Significant regional development has been taking place on aspects such as simplifying administration and decentralization, commercial system reform, especially state-owned enterprises reform and finance reform, which fully reflects that Shandong has been improved steadily under the innovation-driven strategy. While on the other hand, it is not difficult to see that comparing with other economic strong provinces in China, there is still a certain gap for Shandong to improve, which has the theoretical and practical significances on the research of innovation-driven power of Shandong Province.

Objectively to say, despite the high downward pressure, various economic precautions have been taken under all sorts of difficulties, to ensure the economic stability and improvements of Shandong province. Innovation-driven strategy is a must to promote transformation development.

Since ancient times, Shandong Province has been taking a unique geographical position with both active sea transportation of coastal areas and multiple economic patterns of inland areas, which is suitable for implementing and developing innovation-driven strategy. On our way to establish an innovative country, especially under the driving strategy on which General Secretary Xi Jinping and new generations of national leaders emphasize, innovation-driving is a significant developing strategy of China's new developing direction. During the process of Shandong's economic transformation on next step, examples such as constructions of New Eurasia Continental Bridge, China-Mongolia and Russia international aisle will be treated as a reference, and to support the Rizhao Harbor to be constructed as an ocean exit of Mongolia, as well to try to open "QingdaoXinjiang-Europe" and "Qingdao-Manzhouli-Europe" express freight train shifts. Under the influence of innovation-driven strategy, the regional layout of Shandong has achieved the "Two districts, One circle and One belt”.

The impacts of innovation-driven strategy of Shandong Province on innovation efficiency can be researched and proved on aspects as follows: 
The measurement of Shandong's innovation efficiency is mainly to use ratio of the variable value innovation output caused by quantitative value of innovation input. Each region of Shandong varied a lot from one another, either on development structure or comprehensive strength. Comply with the important speech spirit of General Secretary when he Inspected Shandong in 2014, Shandong Province has been implementing innovation-driven strategy from multiple levels since then, and there have been great improvement on either environment innovation or talents team cultivation.

\section{Talents development system of integrating "Project, Paltform, Talent" is established in Shandong Province, which definitely improves the cultivating periods of talents.}

The integrating system of “ Project, Paltform, Talent” is firstly led by projects to introduce talents and then provide suitable platforms to them, so as to manage the overall implement of the whole project. Firstly, the talent introducing direction of Shandong is defined, and through the analysis of talent resources structure, to introduce talents under consideration of overall quantities and market values, which could avoid the waste of talent resources. At the meantime, the introducing of talents can also bring in economic promoting projects, which will make the platforms of enterprises or government more meaningful under the double effect of both talents and projects. Driven by factors such as joint public relations, patented technology transfer, commissioned development, team introduction and core talents, Shandong Province has now become an aggregate carrier of innovative talents. Through the demonstration of various industrial parks and pioneer parks, the cultivation of high-end talents at all levels needed by our province. The accomplishment of the integrating system of “ Project, Paltform, Talent” is an important index of Shandong's innovation efficiency improvement.

\section{The innovation technology achievements transform policy has been reinforced in Shandong Province.}

It has been a both old and new problem to Shandong Province that the technology achievements transform rate is comparitively low. The so-called technoloy achievements transform rate means the professional quantity which has already fished transformation divied by the qauntity of overall technology ahchievements. Not all technology achievements, however, have the necessity to be transformed, under the reasonable market mechanism of specialized person to do specialized work in Shandong Province, especially there have been many new policieslaunched since 2014, which promoting the new technology ahchievements trasformation. A popular trend focusing on technology achievements transformation has been formed, there has been a series of problems such as to contribute technology ahchievement transorming law and enhance technology reform. This trend reflects the high expctation of Shandong Province on technology tranformation, even the hope to become strategic power of strategy driving. It is a good news worthy of refference that some enterprises and colleges in Beijing are able to handle their own scientific research achievements, and $70 \%$ of the profit can be covered to personal income. Thus, in the future, when we mention innovation-driving in our province, this kind of interest definition should be made clear, and the boundaries of property rights should be broken through during the old system reform. Since 2014, our province has won 23 natinal technology achievments awards by the way of cultivating transforming methods, and the patent application qauntity is also increased year by year, of which the Haier Group' patents have reached the amount of 804, and Jinan ranks the top with the patent amount of 5779, then Qingdao the sencond with the patent amount of 4603, meanwhile of all the patents, the invention patents take the key position with an increasing number, which also reflects that our province's patent structure is also under contant optimization and improvement with the help of innovation-driven strategy. 


\section{The resource allocation efficiency of innovation-driven investment has been intensifed.}

\subsection{The investment of innovation fund support need to be greatly improved.}

The current innovation fund support is invested mainly in the way of subsidized interest and gratuitous funding, therefore, industrial structure adjustment and upgrading is demanded under this background. Through reinforcing innovation and reform of traditional enterprises and directing new industry development, to integrate all kinds of reginal strengths, so as to fully join together innovation technology with talents, especially the cities of Shandong Peninsula, such as Jinan and Qingdao with unique resources and geographical advantages that could radiate to lead other regional development.

\subsection{The investment of innovation talent's human capital need to be enhanced.}

With the promotion of innovation-driven strategy, the shortage of innovation talents has been a pain point of the entire society. The need of innovation talents depends on the cultication from colleges and universities, so the cultivating system of innovation talents should be emphasized on the colleges and universities, focusing on either cultivating within the colleges and univertsities, or coopertating with enterprises to train and cultivate talents, to solve the problem of human capital. As to the college innovation resources, ways can be launched from the initial courses setting-up to the innovation thought trainings. Colleges and universities are places with most innovation and passions, and the students are also at the suitable age and intelligence level to be culitvated as innovation talents and resource storage.

Meanwhile, the internal innovation talent transformation within enterprises is also of great significant. Innovation talents are the greatest wealth of enterprises, whereas the enterprises are the biggest stage of talents, so the internal cultivation and resource invest is particularly important. The enterprises require not only the amout of innovation talents, but more importantly should focus on the quality of them. It is a new integration of talents of innovation, an intelligent strategy as well to enhance the talent cultivation.

\subsection{The technology platform should be promoted to large-scale construction, and the technology innovation ablility should be improved.}

In the view of Shandong Province current suituation of innovation platform consturction, the key point to improve technology innovation ability is to establish technology innovation service platform. In recent years, there have been certain work implemented on establishing technology innovation platform, such as the technology planning on-line management system, technology achievement on-line registeration system, expert database of Weifang City, which have achieved the on-line application and appraisal of technolofu project planning and achievements, to simplify the procedures and shorten the periods of transformation. But the current platform construction lacks unified planning, thus the integration the improvement of technology platform will help the establishment of a "one-stop" innovation service platform with multi-function of socialization, specialization and networking. Through the establishment of technology innovation service platform, the scattered resources could be relocated and utillized in a more reasonable and efficient way, to improve the innovation efficiency of our province, and to promote the construction of an innovative province.

This thesis is to analyse various factors which are influencing the innovation efficiency of Shandong Province under the innovation-driven strategy, the premise of innovation driving is to conduct under the background of new economic development, with the innovation strategy as the core driving power to promote the characteristics of endogeny, innovation and sustainability, we believe that Shandong Province will achieve contious and high-efficient improvement under the innovation-driven strategy. 


\section{References}

[1] Ajzen, The theory of planned behavior. Organizational Behavior and Human Decision Processes, 2001(9).

[2] Barrick, MR, Mount, M.K.Effects of impression management and self-deception on the predictivevalidity of personality. Journal of Applied Psychology.2006(81)

[3] Zhizhong Yin. Application of Innovation Efficiency Research [J]. Inner Mongolia Science and Technology and Economy, 2008177 (23) 101-103. 